\title{
What Does "Education" Mean: Cultural Values in Educational Language
}

\author{
Mark Honegger* \\ University of Louisiana at Lafayette \\ *mark.honegger@louisiana.edu \\ Received : 2020-07-15 \\ Accepted : 2020-11-29 \\ DOI: $10.46303 /$ jcve.2020.12
}

\begin{abstract}
How to cite this paper: Honegger, M. (2020). What Does Education Mean: Cultural Values in Educational Language. Journal of Culture and Values in Education, 3(2), 42-53. doi.org/10.46303/jcve.2020.12
\end{abstract}

This is an Open Access article distributed under the terms of the Creative Commons Attribution 4.0 International license (https://creativecommons.org/licenses/by/4.0/)

\section{Abstract}

This article provides an example of how the methods of Natural Semantics Metalanguage can be used to deconstruct and interrogate educational theory by converting key terms such as "education" into simpler meanings that are present in every language of the world. This process connects educational debate to the cultural understandings of education that inform both everyday discourse as well as educational theorists themselves. The views of Paulo Freire and Betsy DeVos are compared using NSM, and the two are found to share an important similarity in their stances on education.

Keywords: Natural Semantics Metalanguage, educational theory, lexical meaning

\section{Introduction}

Jim Cummins (2000) introduced his seminal work on bilingual education, Language, Power and Pedagogy, by reminding us that theory is always a dialogue. Its meaning comes from the conversation that takes place between insiders and outsiders (e.g., university researchers and teachers in the classroom), or between one theory and the body of theories that preceded it. He goes on to affirm:

Shared understandings, assumptions, and conventions underpin both the

generation of theory and its elaboration and refinement through dialogue. (1) [emphasis added]

It is easy to gloss over the difficulties inherent in what might seem to be an uncontroversial observation by Cummins. Humans assume that when they speak to people in the same language, they all share the same basic meanings of the words they are using. However, it is clear that we often engage in discourse but don't share the same meanings with our interlocutors. Witness the debates today over the phrase, "Black Lives Matter." It is easy to attribute the controversies around the movement to mere political differences, but it is more than that. There is also a meaning difference that keeps us from entering into shared dialog with one another. People in the U.S. do not attribute a common meaning to the phrase, and this complicates the discourse and makes it virtually impossible to find common ground or 
solutions to the many social problems the movement highlights. Some people say "Black Lives Matter" means "society has failed to value Black lives in the past and today." Other people say the phrase means that "Black lives matter, but other lives do not equally matter because they are not mentioned," and thus these interpreters often quickly add a further statement such as "All lives matter," or "Police officers' lives matter."

In addition to the meaning differences that can exist even in the same society, there is also the important consideration of the unconscious cultural component of the majority of our words. This is an even thornier problem. Because our own culture tends to be invisible and unconscious to us; like the water that a fish swims in, it is an even more difficult component to surface in our ideological discussions. One's culture appears to be a default setting for the way the world should operate, and so people blithely assume that their words and concepts are universal categories of human experience. Nothing could be farther from the truth.

However, we do not have to be mere victims of our language. It is possible to investigate linguistic differences and the cultural bases that underly our language and discourse. This paper will argue for applying the concepts of Natural Semantics Metalanguage to study the language use of educational discourse in order to determine whether or not there are common meanings that link interlocutors and to surface the hidden cultural bases of our language (Wierzbicka, 1972, 1980, 1996; Goddard, 2018). For a partially sympathetic criticism of the framework, see Jackendoff (2007). It is a framework that provides a more objective basis for studying meaning, an especially crucial element when critiquing ideological discourse. NSM has been adapted for teaching science and history to elementary school children (Wierzbicka, 2018; Christian 2018). It has been used to further diplomacy and discussions of human rights across speakers of different languages (Maley, 2018; Mooney, 2018). It has also been previously applied to education in Alexander (2009), whose work on the words "quality" and "standards" showed how they carried little content but had many implicatures in educational discourse. That is, they were like buzz words in political discourse, such as democracy and freedom that are intended to evoke positive feelings without their content making a serious contribution to content of a discourse

\section{Discussion}

NSM is based on decades of cross-linguistic research across diverse languages both linguistically and culturally. It consists of 65 semantic primes that are asserted to be universal pieces of every language in the world. The table for English is given below. Primes are presented in all capitals:

Table of Semantic Primes-English version

Substantives:

I, YOU, SOMEONE/PERSON, SOMETHING/THING, PEOPLE, BODY

Relational substantives:

KIND, PART

Determiners:

THIS, THE SAME, OTHER/ELSE

Quantifiers:

ONE, TWO, SOME, ALL, MUCH/MANY 
Evaluators:

GOOD, BAD

Descriptors:

BIG, SMALL

Mental Predicates:

THINK, KNOW, WANT, FEEL SEE, HEAR

Speech:

SAY, WORDS, TRUE

Actions, events, movement, contact:

DO, HAPPEN, MOVE

Location, existence, possession, specification:

THERE IS/EXIST, HAVE

Life and death:

LIVE, DIE

Time:

WHEN/TIME, NOW, BEFORE, AFTER, A LONG TIME, A SHORT TIME, FOR SOME TIME, MOMENT

Space:

WHERE/PLACE, BE (SOMEWHERE), HERE, ABOVE, BELOW, FAR, NEAR, SIDE, INSIDE, TOUCHING

Logical concepts:

NOT, MAYBE, CAN, BECAUSE, IF

Intensifier, augmentor:

VERY, MORE

Similarity:

LIKE (AS, HOW)

Primes exist as words or common phrases in every language. They are both universal and non-reducible. That is, they cannot be analyzed into any simpler components. For example, the prime GOOD cannot be defined in any simpler terms than itself. If someone was pressed to define good, they might give descriptions like 'positive,' or 'pleasing' or 'valued.' However, such definitions are more complex than 'good,' and they do not have equivalent terms in all languages (Goddard, 2018). Thus, primes are claimed to be the building blocks of language and of human thought. This has the potential to add a more objective basis to the analysis of thought systems because it can eliminate or reduce culture-specific perspectives.

NSM constructs explications of words using a simple syntax consisting of these semantic primes; in essence, each word is a simple narrative. A sample of an explication used in an educational context is given for the phrase the sky (Wierzbicka, 2018).

the sky

a very big place,

it is above all the places where people live in all places where people live,

people can see this very big place they can see it far above the places where they live 
NSM also avoids the problem of circular definitions, which plagues a lot of dictionaries. For example, the 2012 Cobuild Learner's Dictionary defines 'part' and 'piece' as follows:

Part: Part of something is a piece of its

Piece: A piece of something is a part of it

According to NSM, PART is a universal prime that cannot be deconstructed into anything simpler.

Research is carried out by examining how a word is used across a language community in multiple contexts. This can be done through corpus work, looking up a word in an assembled corpus and examining the context of each use. A good example for modern English is the Corpus of Contemporary English-COCA--(www.english-corpora.org), which contains over one billion words of data from the years 1990-2019. NSM research especially looks for rich contexts that 'explain' the target word. This can include synonyms or antonyms that are paired with the target word. What is the target word treated as similar to in different contexts? Does the word have an opposite term?

Another piece of evidence is to look for collocations, reoccurring phrases it appears in. What other words does it co-occur with? Are there certain grammatical constructions that commonly host the target word.

\section{Happiness and Pain}

The English words happiness and pain will be used as an example of how this kind of research has been carried out. Everything else besides semantic primes is a culture-specific item. That suggests that the vast majority of words in every language are culture-specific constructions so that literally, to learn a language is to learn a cultural point of view. Many English speakers are taken aback by what is not on the list of semantic primes. This includes English words like 'happiness," 'right and wrong,' and 'fair,' For example, while GOOD and BAD exist in every language, the words/concepts "right" and "wrong" do not (Wierzbicka, 2006), which is surprising to many English speakers, who feel that they are talking about universal human concepts.

A good example of the cultural perspective inherent in words can be seen by comparing the English term happiness with its translation equivalents in other languages. Goddard and Wierzbicka (2014) discuss how much research has treated the concept of happiness as a universal that can be used to study values and emotions around the world (e.g. McMahon, 2006). However, words like happy and happiness turn out to encode certain Anglo English values that are far from being universally shared. Goddard and Wierzbicka show that the meaning of happiness has evolved over a number of centuries, but today it can be explicated as follows:

\section{happiness}

a. it can be like this:

b. someone feels something good for some time,

c. like people feel at many times when they think like this:

d. "something good is happening to me now, as I want

e. I can do something now as I want

f. this is good" 
This explication rests on the following concepts. Happiness describes a feeling good because good things are happening to a person and $\mathrm{s} / \mathrm{he}$ is able to do things as they please. Also important is the idea that this is a common feeling ("like people feel at many times"), and it is a feeling that lasts "for some time."

It can be surprising to English speakers to find out that this seemingly obvious emotion is not universal to all cultures and languages. For example, the German equivalent is Glück, related to the English word luck; it connotes the idea of "very good feelings" that do not last "for some time." This can be seen in the contrasting expectations Goddard and Wierzbicka present in the following quotes:

What we call 'happiness' in the strictest sense comes from the (preferably sudden) satisfactions of needs which have been dammed up to a high degree, and it is from its nature only possible as an episodic phenomenon.... Our possibilities of happiness are already restricted by our constitution. (Freud, 1949)

In contrast to Freud's perspective, the poet Alexander Pope wrote,

Oh, happiness! Our being's end and aim!

Good, pleasure, ease, content! Whate'er thy name.

That something still which prompts th' eternal sigh,

For which we bear to live, or dare to die ...

The difference between "good feelings" and "very good feelings" might seem to be slight, but it is a bigger difference than English speakers might realize, because it is connected to cultural expectations. In Anglo English cultures, people expect to be happy and consider it normal to be happy, and they seek happiness as their legitimate birthright. In German culture (and many others), Germans do not expect Glück or treat it as normative (Glück is etymologically related to the English luck) because it denotes a stronger feeling that happens more rarely. Goddard and Wierzbicka also cite the following quote from Nietzsche:

Man does not strive after happiness, only the Englishman does that (qtd in Nussbaum, 2004)

They point out that bonheur in French and sčast'e in Russian convey an idea of good fortune and subjective feeling together so that in French, one can say Quel bonheur! To describe when something really good happens to a person. Yet the equivalent What happiness! is not used in English to convey the idea of an unexpected good fortune occurring.

In Tibetan, the word bdewa, which corresponds to happiness in works like the Dalai Lama's The Art of Happiness: A Handbook for Living (Dalai Lama \& Cutler, 1998), focuses exclusively on internal feelings and thoughts rather than external circumstances, and it connotes the absence of negative feelings toward other living beings rather than the presence of positive feelings as English happiness conveys.

When one looks at happiness and its equivalents across languages, one can raise a number of questions that show how such words differ in important ways:

How long does happiness last?

Does it focus on an internal subjective state or external events?

Does it focus on the presence of good feelings or the absence of bad feelings?

Does it refer to freedom of action?

Does it involve moral obligations to others? 
Is it a goal? What are the experiencer's expectations?

Does it refer to good or very good things?

A second example of words/concepts that are not universal is the English word pain and its translation equivalents. In an increasingly interconnected world, a lot of research has been done on this subject in order to deliver good medical care to the culturally diverse set of people who migrate across national boundaries. In a western context, the default understanding is that pain is a universal concept; however, NSM research has shown that there are significant differences in how different languages and cultures conceptualize what American English speakers describe as pain. Goddard and Wierzbicka (2016) give the following basic explication.

She felt pain.

a. she felt something bad at that time

b. like someone can feel when it is like this:

c. something bad is happening to a part of this someone's body

d. this someone feels something bad in this part of the body because of this

e. this someone can't not think like this at this time: "I don't want this"

Notable aspects here include that the English pain includes the concepts FEEL, THINK and WANT. The experiencer feels bad in a way so that the person does not want the thing and thinks accordingly. The explication also covers both physical and mental pain ("feel when it is like this" in (b)). Goddard and Wierzbicka point out that the opposite of pain in English is pleasure, which also covers both physical and mental states.

The French word douleur seems similar to pain, but there are important differences. While both words can cover both physical and mental experiences, the opposite of douleur in French is bonheur ("happiness") rather than pleasure as in English, as the following examples Goddard and Wierzbicka produce.

Tu enfanteras dans la douleur, tu allaiteras dans le bonheur.

"You will give birth in douleur [pain], you will nurse your child in happiness."

Ma vie est tristement belle. Des averses de bonheur. Des cyclones de douleur.

"My life is sadly beautiful. Showers of happiness. Cyclones of douleur [pain]."

Some other key differences are that douleur suggests a greater intensity of bad feeling than pain. Also, pain tends to be localized in the body ("pain in the neck") while douleur normally is not. Taken altogether, one can see that French and English speakers in a cross-cultural situation will not necessarily identify the same things as pain, a potentially serious issue when it comes to seeking medical treatment.

\section{Two meanings for education}

To demonstrate how NSM can be used in educational discourse, I will present a preliminary investigation of the word education in English. This word is a common noun in everyday unreflective conversation whose meanings can be elucidated in those contexts. At the same time it is also a word whose meaning is contended for by educational theorists, just as the meaning of the phrase "Black lives matter" is contended for. Comparing the everyday meanings and uses with the argued-for meanings of educational theorists gives us a way of 
considering more carefully what is at stake in the various conceptions of education in academic debates. It turns out that it can even show us how two very different approaches to education, such as the views of Paulo Freire and Betsy DeVos actually share something in common.

The American Heritage Dictionary, $4^{\text {th }}$ ed. gives these first three definitions for the verb educate:

To develop the innate capacities of, esp. by schooling or instruction.

To provide with knowledge or training in a particular area or for a particular purpose.

To provide with information; inform.

The noun education then refers to the act or process of educating or being educated. To educate someone is similar to teaching someone, and to be educated by someone is similar to being taught by someone. That would suggest an explication like the following.

\section{A educated $B$}

a. Someone B did not know something $X$.

b. Someone A said something $X$ to someone $B$ for some time.

c. After some time, someone $B$ knew something $X$, because someone $A$ said something $X$.

d. After some time, someone $B$ could do something $Y$, because they knew something $X$.

This explication covers the following components. The student (Someone B) did not know something at first (a). The teacher (Someone A) communicated something to the student (b). The student learned the material (c). The student was now able to do something because they learned the material (d). It is reflected in an expression like "to get an education" which makes reference to the student's newfound ability to do something they couldn't do before. An explication like this takes in what Anglo English speakers think of with regard to education. This partial explication would be a part of one meaning which I will call education 1 .

However, if we look at lots of examples of the word education, we will also find some other aspects of the word. Most of the following data comes from the Corpus of Contemporary American English (COCA). This corpus contains more than one billion words across eight different genres from 1990-2019. It also has a number of useful tools, such as the ability to identify common phrases which contain a given target word. A preliminary look at the data reveals that one of the most salient characteristics of the word in English today is that it combines with a plethora of adjectives and nouns. A partial list is given below:

music education higher education arts education adult education physical education primary education continuing education health education online education college education
STEM education post-secondary education sex education K-12 education elementary educationHIV/AIDS education correctional education distance education technology education special education bilingual education remedial education multicultural education, etc. 
This combinability is reflected in the American Heritage Dictionary's third definition for the word education,

A program of instruction of a specified kind or level: driver education.

This common usage shows us a couple of important things. First, education has become increasingly specialized, a reflection of the increasing specialization that has developed in all of society. We think less about education in the abstract and more in terms of these very specific kinds of education. Our need to continually differentiate them suggests we think more in terms of differences among them and less in terms of a unified phenomenon.

Second, the prevalence of these phrases also suggests that when we use the word education, we are often thinking about institutions and associating it with the organizations and infrastructure that supports it. There is evidence that the word education is frequently used in contexts where an entity is in focus and only secondarily the concepts of teaching and learning. An explication for what I will label as education 2 would include the following description.

\section{Education 2}

\section{Something $X$}

Many people are a part of something $X$.

There are a number of pointers to this institutional emphasis in the word. The word education is frequently used in names and titles. There is a "U.S. Department of Education" but not a "U.S. Department of Learning" or a "U.S. Department of Teaching." This shift to organization and infrastructure is probably also why the word is connected with formal more than informal teaching and learning. This can be seen in an example from COCA like the following,

"She can always either teach or choose another path. Education alone with no other skill set is a bad place to be."

This quote makes reference to learning in a formal context. There is also the absence of possible phrases in English, where we speak of "home schooling" but not of "home education," although the explication given above for education ${ }_{1}$ would certainly be congruent with the latter.

A final observation that shows how an institutional concept is often in focus is that we find occurrences of the word that make reference to students not being able to do something as a result of their education, such as the two below from COCA.

An education alone may not take you out of poverty. It may not end poverty. Education alone probably won't help you get hired.

The previous explication of education ${ }_{1}$ included the following description:

d. After some time, someone B could do something $\mathrm{Y}$, because they knew something $\mathrm{X}$. 
That is, the generic concept of education included the idea that students both learn something and are able to do something because of their learning. It is notable then that there are numerous instances where education is described as not leading to students being able to do something or not leading to a benefit that we would expect them to have as a result of learning. These contexts confirm that there also exists an education, a second cultural usage which focuses on formal, institutional aspects rather than pure teaching and learning. In other words, education ${ }_{1}$ conveys the idea of successful teaching and learning. Education 2 does not include this because its focus is elsewhere.

I suggest that these two explications in education 1 and education 2 which reflect everyday meanings and cultural understandings for Anglo English society can be used to deconstruct the educational theory and discourse in specialized communities. For example, both explications can help us better understand a construct like Paulo Freire's banking notion of education that he critiques and wishes to replace with what he calls authentic or problemposing education. In Pedagogy of the Oppressed (Freire, 2000), he describes the banking notion as follows:

Education thus becomes an act of depositing., in which the students are the depositories and the teacher is the depositor. Instead of communicating, the teacher issues communiques and makes deposits which the students patiently receive, memorize, and repeat.

Facts and information move from the head of the teacher to heads of the students like a person would deposit money into their bank account.

In contrast, authentic or problem-posing education takes place when teachers stimulate their students to seek problems and solve them, especially problems related to oppression and social injustice. The emphasis here is not on mastering a body of content (banking) but on developing a critical way of thinking and being in the world.

How does Freire's thinking line up with the explication of education ${ }_{1}$ ? On the surface, this explication might seem to be encoding the banking notion of education, but it does not. Crucially, education 1 does not specify the content of what is taught nor how the teaching is taking place ("Someone A said something X to someone B for some time"). It simply tells us that the teacher said something that enabled their students to do something. NSM helps us to recognize that Freire is critiquing what is being taught and how it is taught, not the idea that the teacher is a catalyst in the process. We could put Freire's emphasis into the explication of education 1 to show this.

Freire's Authentic education

a. Someone B did not know something X (critical thinking).

b. Someone A said something $X$ (critical thinking) to someone $B$ for some time.

c. After some time, someone B knew something $X$ (critical thinking), because someone

A said something $X$ (critical thinking).

d. After some time, someone B could do something $Y$ (seek social change), because they knew something $X$ (critical thinking).

In other words, Freire's position is in harmony with this cultural understanding of education that is part of everyday discourse.

We can also notice that Freire's work is very much related to the explication of education 2 as well. Throughout Pedagogy of the Oppressed, there is a thoroughgoing critique 
of the institutional aspects of education because Freire sees the institutions of education as perpetuating oppression and injustice in the broader society. As he says,

Submerged in reality, the oppressed cannot perceive clearly the 'order' which serves the interests of the oppressors whose image they have internalized. banking education maintains and even stimulates the contradiction [unequal power between teacher and student] through the following attitudes and practices, which mirror oppressive society as a whole.

It turns out that Freire's educational theory is consistent with the cultural understandings of both education $_{1}$ and education 2 , not contrary to them, and this is what enables people to understand and consider and potentially agree with his theoretical perspective.

I now turn to someone who appears to be completely different from Freire in the person of Betsy DeVos, Secretary of Education in the administration of Donald Trump. DeVos is not a theorist à la Paulo Freire or Jean Piaget or Lev Vygotsky, but she does have a stance on education that can be examined via NSM. In the Q\&A section of her webpage betsydevos.com, it says, "the status quo is not acceptable." The status quo she has in mind is to reshape the educational landscape in favor of charter schools, private schools, and the use of federally-funded vouchers to financially support them. She is quoted in a Washington Post article,

[Education] is a closed system, a closed industry, a closed market. It's a monopoly, a dead end. And the best and brightest innovators and risk-takers steer way clear of it. As long as education remains a closed system, we will never see the education equivalents of Google, Facebook, Amazon, PayPal, Wikipedia, or Uber. (Strauss, 2016)

Unlike Freire, the specifics of what is taught and how it is taught are not central to her educational perspective. What is central to DeVos is that she is very much criticizing the institutional aspects of education, because she views its current institutional framework to be the primary obstacle to learning. Both Freire and DeVos share in common a deep sense of dissatisfaction with the institutional side of education, albeit from very different perspectives.

Here is why this is important to understand. Both Freire and DeVos want to dismantle and change the institutional makeup of education. What enables their perspectives to be heard and sometimes accepted by other people is this: even though overall they have very different approaches to education, both approaches are based on the same cultural understanding encoded in education 2 . Corpus evidence suggests that the word education is often connected to two foci, successful teaching and learning (education ${ }_{1}$ ) and institutional aspects (education 2 ).

Why do people like Freire and DeVos gain a hearing, even though their overall perspectives are radically different? They do because their specific emphases are still connected to the cultural understandings found in everyday uses of education. The content of education $_{1}$ shows that people are still attuned to effectiveness of education, that students know something and are able to do something because of what they were taught. The content of education 2 may be even more telling, because it is an example of how institutions in general have grown in importance in human existence, and how they exert ever more control over the individual, along the way becoming ever more complicated. Because of their centrality to all that we do today, institutions are also easy targets for criticism. Anyone who has had a run in with a school's front office, or misunderstood a poorly worded school memo, 
or been frustrated by some school paperwork, or been critical of a child's assignment or grade, is a prime candidate to be receptive to an approach that says the current institutional framework of education is at fault.

There is much, much more to be said about the cultural underpinnings of the word education in modern English, but even this short study reveals a few considerations that should be considered when discussing culture and values in education. The word is frequently used with a focus on the formal organizational and institutional aspect of education rather than the pure idea of successful teaching and learning. Education increasingly is divided into distinct fields rather than seen as a unified entity, and this also mirrors the formal and institutional bases that are front and center in much talk of education. In ideological discourse about education within academic discourse communities, this study suggests that educators not only should debate their competing ideas of education, but they should also consider how education is talked about in ordinary discourse by the broader society in order to consider how their positions relate to the concerns of a wide range of people. NSM can help us take our intellectual debates into the real world, the crucible in which they must ultimately be tested. 


\section{References}

Alexander, D. (2009). Quality and standards in higher education discourse: A linguistic overview. Proceedings of AUQF2009.

Christian, D. (2018). Big history meets Minimal English. Minimal English for a global world: Improved communication using fewer words (pp. 201-224). Palgrave Macmillan.

Cummins, J. (2000). Language, power and pedagogy: Bilingual children in the crossfire. Multilingual Matters.

Dalai Lama XIV \& Cutler, H. (1998). The art of happiness: A handbook for living. Hodder.

Freire, P. (2000). Pedagogy of the oppressed (30 ${ }^{\text {th }}$ Anniversary ed.). Continuum.

Freud, S. (1949). Civilisation and its discontents. Hogarth Press.

Goddard, C. (2018). Minimal English for a global world: Improved communication using fewer words. Palgrave Macmillan.

Goddard, C. \& Wierzbicka, A. (2014). Words and meanings: Lexical Semantics across domains, languages and cultures. Oxford University Press.

Jackendoff, R. (2007). Conceptual semantics and natural semantic metalanguage theory have different goals. Intercultural Pragmatics 4(3), 411-418.

McMahon, D. (2006). Happiness: A history. Atlantic Monthly Press.

Maley, W. (2018). Minimal English and diplomacy. Minimal English for a global world: Improved communication using fewer words (pp.71-93). Palgrave Macmillan.

Mooney, A. (2018). Torture laid bare: Global English and human rights. Minimal English for a global world: Improved communication using fewer words (143-167). Palgrave Macmillan.

Nussbaum, M. (2004). Mill between Aristotle and Bentham. Daedalus, 133(2), 60-68.

Strauss, V. (2016, December 21). To Trump's education pick, the U.S. public school system is a 'dead end.' The Washington Post. https://www.washingtonpost.com/news/answersheet/wp/2016/12/21/to-trumps-education-pick-the-u-s-public-school-system-is-adead-end/

Wierzbicka, A. (1997). Understanding cultures through their key words: English, Russian, Polish, German and Japanese. Oxford University Press.

Wierzbicka, A. (2006). English: Meaning and culture. Oxford University Press.

Wierzbicka, A. (2018). Talking about the universe in minimal English: Teaching science through words that children can understand. Minimal English for a global world: Improved communication using fewer words (pp. 169-200). Palgrave Macmillan. 